NBER WORKING PAPERS SERIES

ENERGY TAX CREDITS AND RESIDENTIAL CONSERVATION INVESTMENT

Kevin A. Hassett

Gilbert E. Metcalf

Working Paper No. 4020

\author{
NATIONAL BUREAU OF ECONOMIC RESEARCH \\ 1050 Massachusetts Avenue \\ Cambridge, MA 02138 \\ March 1992
}

We are grateful to Lis Coutts, Dan Feenberg and Joel Slemrod for help with data construction and to Alan Auerbach, Giuseppe Bertola, Harvey Rosen, and especially Avinash Dixit for discussions and comments on earlier drafts of this paper. This paper is part of NBER's research program in Public Economics. Any opinions expressed are those of the authors and not those of the National Bureau of Economic Research. 
NBER Working Paper \#4020

March 1992

\title{
ENERGY TAX CREDITS AND RESIDENTIAL CONSERVATION INVESTMENT
}

\begin{abstract}
We model the decision to invest in residential energy conservation capital as an ireversible investment in the face of price uncertainty. The irreversible nature of this investment means that there is a value to waiting to invest (an option value) which helps explain the low rate of conservation investment as a result of the residential energy tax credit. Simulations suggest that a tax credit of the type implemented from 1978 through 1985 will not increase conservation investment significantly.

We investigate the empirical evidence on the effectiveness of credits using data from a panel data set of roughly 38,000 individual tax returns followed over a three year period from 1979-1981. Unlike previous work, we find that the energy tax credit is statistically significant in explaining the probability of investing. Our estimates suggest that increasing the federal credit by 10 percentage points would increase the percentage of households claiming the credit from $5.7 \%$ to $7.1 \%$.
\end{abstract}

Kevin A. Hassett

Graduate School of Business

Uris Hall

Columbia University

New York, NY 10027
Gilbert E. Metcalf

Department of Economics

Fisher Hall

Princeton University

Princeton, NJ 08544-1021

and NBER 


\section{Introduction}

There is an extensive literature which documents that a significant number of energy conservation investments, which by any reasonable measure have a very high rate of return, are not undertaken (see, for example, williams and Ross (1980) and Carlsmith et al (1990)). This literature in the past has argued that a variety of market barriers, e.g. fuel price distortions, lack of information, etc., discourage these investments ${ }^{1}$.

While many of these market barriers may exist, we believe that an important explanation for this low rate of investment is the uncertainty over the path of future energy prices. Key to this explanation is the recognition of the irreversible nature of many home energy improvements which frequently involve structural alteration of one's residence. This paper develops a model of home energy investment which formally incorporates this feature. ${ }^{2}$ We then apply this model to evaluate the effectiveness of an energy tax credit for conservation investment along the lines of the Residential Energy Tax Credit which was in effect from 1978 through 1985. We first develop a set of energy price and investment simulations based on the model to investigate how

1 Sutherland (1991) summarizes and raises objections to many of the common market failures that are proposed to explain the "energy paradox".

2 In a recent paper, Jaffee and Stavins (1991) attempt to incorporate many of the market barrier features described above into an economic model. They focus on the relative merits of price based controls versus regulation to increase conservation investment and do not consider irreversibility and price uncertainty in their model. 
uncertainty over future prices affects the decision to invest in conservation capital. We also consider how different tax policies might affect the rate of investment. We calibrate these simulations to aggregate data under a variety of assumptions about the nature of stochastic prices facing investors. The simulation results based upon the moments of the relevant price processes replicate the pattern of residential energy conservation investment observed in the United States during the late 1970 s and early 1980 s and suggest that it is unnecessary to appeal to myriad ad hoc market failures in order to explain the "energy paradox". Irreversibility and uncertainty alone can explain the observed adoption rates quite well, and we view both to be reasonable features of a model of residential conservation investment. In order to evaluate our approach more thoroughly, we then analyze a large data set on individual federal tax returns in the United States over the three year period 19791981. This data set has extensive information on energy conservation investment made by individuals which, combined with state level energy and weather data, allows us to investigate the impact of conservation incentive programs on individuals' investment decisions. Unlike previous authors, we find, as the theory would suggest, statistically significant tax credit effects on residential conservation investment; the size of these effects is consistent with the predictions of the model.

In the next section we present our model of conservation investment in the presence of price uncertainty. We then provide 
simulation results which explore both the speed of technology diffusion and the size of tax credit effects in our model. Some background on conservation investment incentives at the federal and state level precedes our empirical work. We close with a brief conclusion.

II. A Model of Irreversible Home Energy Improvement

In this section, we sketch out a simple model of the decision to invest in conservation measures to reduce energy consumption. 3 Key to our analysis is the assumption that the investment in energy conservation capital is irreversible. Typical conservation investments include ceiling and wall insulation, storm doors and windows and caulking; the salvage value of any of these investments is likely to be very low. Because of this, as is well known in the literature on irreversible decisions, there is an option value associated with not investing which contributes to a slowdown in the rate of investment.

Assume that the price of energy $\left(P_{1 t}\right)$ varies across individuals and time according to a geometric Brownian motion process :

$$
d P_{1 t}=\mu_{p} P_{1 t} d t+\sigma_{p} P_{1 t} d z_{p} \text {. }
$$

where $z_{p}$ is a standardized Brownian motion (Wiener) process whose change $d z_{p}$ has mean zero and unit variance. The change in $P_{l t}$ over time $t$ has mean $\mu_{p} t$ and variance $\sigma_{p}^{2} t$. similarly, we assume

3 This model could also be used to analyze renewable energy investment. 
that the price of conservation capital $\left(K_{1 t}\right)$ varies over time and (perhaps) individuals according to a geometric Brownian motion process:

$$
d \mathrm{~K}_{1 \mathrm{t}}=\mu_{\mathrm{k}} \mathrm{K}_{1 \mathrm{t}} \mathrm{dt}+\sigma_{\mathrm{k}} \mathrm{K}_{1 \mathrm{t}} \mathrm{d} \mathrm{z}_{\mathrm{k}}
$$

where $z_{k}$ is a wiener process with $d z_{k}$ having mean zero and unit variance. The correlation between $z_{p}$ and $z_{k}$ is denoted by $\rho$.

The lifetime cost of energy use for a risk neutral household is composed of three parts. The first part is the stream of energy costs prior to undertaking an energy conservation investment. The second part is the stream of costs after the conservation investment is made. The third part is the cost of the investment itself. We assume that the household chooses an optimal strategy at time zero to determine when to make the conservation investment to minimize the expected value of the present discounted value of lifetime energy costs (including the conservation capital costs):

(3) $E\left\{\int_{0}^{T} P_{i t} e^{-\gamma_{i} t} d t+\int_{T}^{\infty}\left(1-\delta_{i}\right) P_{i t} e^{-\gamma_{1} t} d t+K_{i T} e^{-\gamma_{i} T}\right\}$. In equation (3), $\gamma_{i}$ is the discount rate for the $i$ th individual, $\delta_{1}$ is the savings in energy costs due to the conservation investment expressed as a fraction of energy costs and $T$, the time at which investment occurs (which could be infinite).

Equation (3) can be rewritten so that the problem becomes one of maximizing expected energy savings:

(4) $E\left\{\int_{I}^{\infty} \delta_{i} P_{i t} e^{-\gamma_{i} t} d t-K_{i \tau} e^{-\gamma_{1} T}+\int_{0}^{\infty} P_{1 t} e^{-\gamma_{1} t} d t\right\}$ Formulated in this fashion, the problem now is clearly one of 
choosing an optimal sequential decision rule which selects the time to make an irreversible investment which has a revenue stream of $\delta_{i} P_{i t}$ per period at investment cost $k_{i t}$. As we show in the appendix, the optimal time to invest in the energy conservation capital occurs when:

$$
\delta_{1} P_{1 T}>\frac{b}{b-1}\left(\gamma_{1}-\mu_{p}\right) K_{1 T},
$$

where

$$
b=\frac{.5 \sigma_{0}^{2}-\alpha+\sqrt{\left(.5 \sigma_{0}^{2}-\alpha\right)^{2}+2\left(\gamma_{1}-\mu_{k}\right) \sigma_{0}^{2}}}{\sigma_{0}^{2}}
$$

In equation ( 6$), \sigma_{0}^{2}$ is the variance and $\alpha$ is the drift of the hybrid geometric Brownian motion process $P_{i t} / K_{i t}$ (see the appendix for details). The term $b$ will be greater than one if $\alpha$ $+\mu_{x}<r$, that is, if the trend in the geometric Brownian motion process of $P_{i t} / K_{i t}$ (adjusted for the trend in capital costs) is less than the individual's discount rate. This condition is essentially the condition that it be optimal for the individual to make an investment in the energy capital in finite time.

As $\sigma_{0}{ }^{2}$ approaches zero, the term $b /(b-1)$ approaches one, and the investment rule in equation (5) collapses to the Marshallian investment criterion that one should invest if the present discounted value of the savings, $\delta P /\left(\gamma-\mu_{p}\right)$ exceeds the cost of investment $K$. With stochastic prices, however, the investment rule is scaled up by the factor $b /(b-1)>1$. Thus, individuals might choose not to invest even though the return substantially exceeds their cost of funds, something consistent 
with the survey data showing "low" responsiveness, because the gain to waiting, summarized by $b /(b-1)$, is high. Moreover, studies (e.g. Hausman (1982)) which ignore the impact of irreversibility on the decision by a homeowner to purchase appliances would necessarily significantly overstate the discount rate used by consumers.

Having established that uncertainty combined with irreversibility can reduce the amount of investment made in conservation capital, we next turn to stochastic simulations of our model, in order to explore more fully the impact of irreversibility on the diffusion of new technologies. We also analyze the impact of tax policy on the diffusion process in this setting.

\section{Simulations and the Rate of Investment}

There has been a substantial literature analyzing the diffusion of technology dating back to Griliches (1957). A stylized fact emerging from this literature is that the adoption of new technologies occurs subject to an $s$-shaped curve ${ }^{4}$. What is striking about the energy conservation experience in the 1970 s is the very slow rate of diffusion of new technologies. This has led to considerable speculation that information about new technologies has not spread sufficiently rapidly or that capital market failures might deter investment. 4 See Jovanovic and Lach (1989) for a review of the literature
on diffusion as well as a theory based on learning by doing. 
One need not appeal to market imperfections, however, to generate extremely slow diffusion processes. Consider the following example. Assume that individuals have identical preferences. If $\delta$ were the same for everyone, then we would observe no investment until equation (5) were satisfied at which point everyone would invest. However, even with identical preferences, there will be a distribution of ex ante expected improvements $(\delta)$. Put differently, the housing stock is heterogeneous and there exists considerable variation in the gains from particular energy improvements. Hence as $P / K$ rises, people who will reap large savings from a particular energy conservation investment will invest first while people with lower expected gains wait for $P / K$ to rise further ${ }^{5}$. To illustrate the diffusion pattern which emerges from our model, we present simulation results from a model where the energy savings parameter, $\delta_{1}$, is normally distributed with mean 0.2 and standard deviation . 1 , values chosen to correspond roughly to existing engineering estimates of the return to these investments.

For the purposes of simulations, we estimated the trend and variance of the price process $P / K$ using data on energy prices and capital over the period 1955 through 1981, the last year of data

5 This is an example of the "probit" type diffusion model (viz. stoneman (1983)). We note, however, that this argument is much more powerful when combined with an assumption of irreversibility, which provides both an s-shaped adoption curve and the potential for extremely slow adoption rates. We also prefer our formulation because the diffusion comes about because of a heterogeneous housing stock, not because of ad-hoc assumptions of preference heterogeneity. 
used in the empirical work described below. The household fuel oil price index was used as a measure of $P$ while the durable commodities price index was used as a measure of $k$. Data were taken from the Economic Report of the President. Assuming that $P / K$ follows geometric Brownian motion, we obtain estimates of $\alpha$ equal to .046 and and $\sigma_{0}$ equal to .093 . In order to help gauge the effect of the irreversibility assumption we also provide simulations assuming there is no uncertainty, which drives the option value to zero. Figure 1 presents the price process and Figure 2 the rate of cumulative investment over a 20 year horizon when $\sigma_{0}=0$. The hurdle rule is the traditional Marshallian one. figure 2 shows that investment rises dramatically with 408 of households making conservation improvements within 5 years and 998 by 20 years.

Contrast this result with the cumulative investment in the case where $\sigma_{0}=.093$. Figure 3 shows the price process and figure 4 the rate of investment. The price process is started at the same value $\left(P_{0}\right)$ as in the certainty case (figure 1 ). With a real discount rate of $.05, b$ equals 1.31 and $b /(b-1)$ equals 4.23 . With these assumptions, the rate of investment is remarkably slow, with many intervening years of no investment at all. Cumulative investment after 20 years is less than $5 \%$. Note that the price both increases and decreases over the 20 year period. Thus there are periods of rapid investment followed by periods of no investment which can last as long as six years.

Figure 5 shows the results of a set of 500 replications of 
the price process and cumulative investment under uncertainty. The trend and variance of the price process is the same in the replications, matching the moments used for flgure 3 . The figure shows that the dispersion in investment increases with time as would be expected given that the price process follows geometric Brownian motion. At the end of the loth year, the mean cumulative investment is $7.5 \%$ with a standard deviation of 4.78 . Minimum investment is $2.5 \%$ and the maximum is $31 \%$. As figure 5 shows, cases with cumulative investment after 10 years as large as $15 t$ are quite rare. Hence we do not attribute our results showing low investment under price uncertainty to the particular price process that we generated in figure 3.

Figures 6 and 7 show the effect of instituting a $15 \%$ tax credit on the purchase of the conservation capital at time $t=1$. For the certainty case (figure 6 ), the stimulation to investment is dramatic. Investment increases from about 27 to 43 as a direct result of the credit. Investment after 5 years is now about 608 versus 408 without the credit. However, with the geometric Brownian motion assumption, the credit is much less effective (figure 7). Investment increases by .2 as a direct result of the credit and by less than 3 after 20 years 6 .

of course, with the investment trigger increased by a factor of 4 , these results are perhaps not surprising. But note that if

6 This result is general. In a series of 1000 replications, the mean increase in investment is .2t at $t=1$ with a standard deviation of .118. The maximum increase is .57\%. 
individuals weighted recent energy price data more heavily when they make subjective estimates of $\alpha, \sigma_{0}$, and $b$, the adjustment factor would be even larger. Using data from 1960 through 1981 gives estimates of $b /(b-1)$ of 7.65 .

The simulation results show in a striking way that uncertainty can sharply reduce investment in conservation capital. Moreover, a tax credit can have a significant effect on increasing investment - to the order of doubling the probability of investing in conservation capital. However, in the presence of price uncertainty, the probability of investing is so low that doubling the investment probability has negligible effects on total conservation investment. In the next section, we turn to a closer examination of the state and federal tax incentives that existed in the late $70 \mathrm{~s}$ and early $80 \mathrm{~s}$ which will provide the basis for an empirical examination of the actual response of residential conservation investment to tax incentive programs.

\section{Tax Policy Toward Conservation Investment}

Tax incentives to stimulate conservation investment existed during the 1970s-1980s at both the federal and state level. As most state programs "piggy backed" on the federal. system, we discuss the latter program in greater detail. We also discuss how previous researchers have tried to measure the effectiveness of the tax incentives at stimulating investment.

The Energy Tax Act of 1978 (ETA78) provided homeowners with tax credits to encourage conservation investment activities such as insulating walls and ceilings, replacing furnace burners and 
ignition systems, storm or thermal windows and doors, installing clock thermostats, and weatherstripping. These investments received a credit of $15 \%$, with a credit ceiling set at $\$ 300$ and could only be taken on houses that were constructed prior to 1977.7

In addition to the federal credit, nine states offered a conservation incentive (either a deduction or a credit) over the period 1979 through 1985 when the federal credit expired.8 These state programs will be important in the econometric work below as they provide variation in the tax price of conservation investment which allows us to identify the importance of the programs in stimulating investment.

Given the broad coverage and low cost of some highly productive improvements, one might think that the credits would be universally claimed. Surprisingly, this is not the case. Table 1 presents information from the statistics of Income on the fraction of returns which claimed the credit for either conservation or renewable energy activities. The credit is most

7 ETA78 also encouraged investment in solar, wind and geothermal energy equipment used to heat, cool, and supply hot water or electricity to the principle residence. These investments received a higher credit, with $30 \%$ of the first $\$ 2000$ and $20 \%$ of the next $\$ 10,000$ qualifying for the credit, with a maximum credit of $\$ 2600$. ETA78 was amended by the Crude Oil Windfall Profits Tax Act of 1980, which increased the tax credits available for renewable systems to $40 \%$ of up to $\$ 10,000$ in expenditure. The credit for these investments was available to all principle residences regardless of when built.

8 Arizona, California, Colorado, Hawail, Montana, and oregon offered credits of some form while Arkansas, Idaho, and Indiana offered deductions. Information on these programs comes from Walsh (1987) and tax forms. 
heavily taken in 1978 where 6.5\%. Of the returns claimed a credit. Note that the energy tax credit was retroactively applied beginning April 20, 1977. Credits for investments made in 1977 could be taken in 1978; hence the data for 1978 cover roughly 20 months. The fraction of returns filing the credit drops from $6.5 \%$ in 1978 to roughly 38 by 1985 , the last year in which the credit could be taken.

One might think that conservation credits might be fraudulently claimed, or that, unaware of the possibility of taking them, taxpayers may fail to claim a credit they ought to. Fortunately, the TCMP audit data allow us to analyze the extent to which mistakes or frauds occur. The 1986 TCMP data indicate that of the 560 million dollars of tax credits claimed in 1985, 531 million were legitimate, and an additional 28 million allowable claims which were not originally reported were discovered. These numbers are typical of those for most items covered by the audit, and indicate that fraud or mistakes will not be an important source of measurement error in the empirical work we present below 9 .

In Table 2, we report the distribution of returns for 1979 by income and the fraction of credit takers in each group along with the fraction homeowners. The probability of taking the credit rises with income and reaches a peak of 15.67 for returns in the $\$ 50,000$ to $\$ 100,000$ group. For the group with AGI less

9 We thank Joel slemrod for providing this information. 
than $\$ 10,000$, the fraction of takers is $1.21 \%$, roughly a third of the fraction of takers in the next income group.

Table 3 reports the fraction of credit takers and mean conservation expenditures by state for 1979 along with the average credit for those who took the credit in each state. The geographic distribution of the propensity to take the federal credit for the most part is not surprising. However, certain states stand out, california most prominently. With the exception of Hawail, California had the lowest fraction of credit takers of all the states. california's state conservation incentive program is unique in offering a very generous credit for conservation activity ( $40 \%$ of costs). However, the credit is net of the federal credit. For most households, it is simply easier to claim the entire $40 \%$ on the state return than claim $15 \%$ on the federal return and the remaining 25 on the state return. Thus the low participation rate in the federal program for california reflects a measurement problem, a problem we address in the estimation strategy below.

Results of previous research on the effectiveness of energy tax incentive programs have been relatively inconclusive. This literature consists of a small series of survey studies, (Pitts and Wittenbach (1981), Carpenter and Chester (1984), Peterson (1985)) and three econometric analyses (Cameron (1985), Walsh (1987), (1989) and Dubin and Henson (1988)). The survey studies indicate that the tax credits are important motivators for purchases of renewable energy improvements, but not for 
conservation.

Cameron does not directly estimate the additional investment resulting from federal and state incentive programs but rather estimates the price elasticity of investment for energy conservation and renewable investment. Using cross section data from the National Interim Energy Consumption survey of 1977-78, she constructs and estimates a nested logit model over many improvement alternatives and finds significant price sensitivity, suggesting that credits might provide an important stimulus.

One problem with the approach used by cameron is that it is assumed that changes in price due to the implementation of tax credits will have the same effect as direct changes in investment costs. This will be true in a world in which the transaction costs of taking the credit are minimal and in which information about the tax incentives are widely dispersed. Moreover, one must have a positive tax liability to benefit from the credit. In the absence of these conditions, the tax credit changes in price may induce less investment than an equivalent direct change in price.

Walsh (1987,1989), using Department of Energy data and state level variation in tax credits, attempts to test directly whether the tax incentives at the federal or state level induce additional conservation investment. He found that the states which had high energy tax credits experienced very low conservation investment activity. In a cross section regression, he finds a significant neqative effect of tax credits on 
investment.

Dubin and Henson, used a cross section of IRS audits for 1979 and related energy conservation activity to state level temperature data and individual characteristics.10 They found that investment increases with income and that it responds to measures, such as "heating degree days", which help predict its return. While the coefficient on a dummy variable for the existence of a state credit for conservation is positive in a regression with federal tax credit claimed as the dependent variable, it is statistically insignificant with a $t$ statistic of roughly .3 .

Thus, the only evidence relating the tax incentives to investment activity suggests that they have been ineffective, although investment does respond to other variables that enhance its profitability. We believe that there are two major reasons why these studies have been unable to find a statistically and economically significant relationship between the tax incentive programs and investment. First there are individual and state specific effects which are likely to be correlated with the explanatory variables. State specific effects include the measurement error noted for California as a result of the nature of the state incentive program. Individual specific effects include individual propensities to invest in conservation

10 The unit of observation in their study is an average of returns from a TCMP cross tabulation. This limits the effectiveness of individual variables. Our data is also IRS data but consists of individual returns. 
equipment. These might include conservation "taste" factors as well as attributes of the housing stock that individuals choose. second, many of the state tax incentive programs are deduction programs. A dollar of deduction reduces taxable income by 1 and tax liability by mere $m$ is the marginal tax rate. Therefore, the tax price of one dollar's worth of investment is $1-\mathrm{m}$. Measuring the tax price accurately for residents of states with deduction incentives is important. We use the NBER TAXSIM state tax calculator to measure the tax price at the individual level. In the next section, we describe our data set and present results from a set of regressions where we measure the responsiveness of residential conservation investment to changes in state tax incentives.

\section{Empirical Work}

As the last two simulations in section III suggest, an important question is whether tax policy can substantialiy affect the decision to invest in conservation capital. We test the effectiveness of tax incentives directly by estimating the effect of state tax incentive programs on the decision to invest in a discrete choice framework. To do this, we exploit the information filed on federal returns by tax payers claiming the federal residential energy conservation tax credit along with variations in state level tax incentives.

The regression estimates are from a reduced form model in which the dependent variable $\left(I_{1 t}\right)$ is a binary variable indicating whether the tax payer has an expenditure for 
conservation investment. We relate this to a vector of explanatory variables which theory suggests should help determine the payoffs to investing. As discussed previously, it is also important to account for individual heterogeneity or fixed effects 11 . Assuming the probability of making the investment has the extreme value distribution, then

$$
P\left(I_{1 t}=1\right)=\frac{e^{\alpha_{i}+\beta x_{i t}}}{1+e^{\alpha_{i}+\beta x_{i t}}} .
$$

Following the suggestion of Chamberlain (1980), we condition the likelihood function on making an expenditure at least once. This latter probability will equal the sum of the probabilities that $I_{1}$ equals $1 ; 2$, and so on. To see how this solves the problem of heterogeneity, consider the probability that $\sum_{t} I_{1 t}=1$ in a two period model where $P(1,0)$ is defined as the joint probability of taking the credit in the first year and not taking it in the second year. $P(0,1)$ is similarly defined.

$$
P\left(\sum_{t} I_{1 t}=1\right)=P(1,0)+P(0,1)
$$

Consider the probability that we observe $P(0,1)$ conditional on the sum being equal to 1 :

11 The likely direction of the fixed effects bias may well explain previous estimates which found the wrong sign on the tax credit variable. If a state is populated by citizens who have a higher than average probability of investing because of unobservables, it may be that that state has a low probability of introducing a credit program. This type of interaction is consistent with the evidence provided below. 
(11)

$$
\begin{gathered}
P\left(0,1 \mid \sum_{i} I_{1 i}=1\right) \\
\frac{\frac{1 *\left(e^{\alpha_{i}+\beta x_{i 2}}\right)}{\left(1+e^{\alpha_{i}+\beta x_{i 1}}\right)\left(1+e^{\alpha_{i}+\beta x_{i 2}}\right)}}{\frac{1 *\left(e^{\alpha_{i}+\beta x_{i 2}}\right)}{\left(1+e^{\alpha_{i}+\beta x_{i 1}}\right)\left(1+e^{\alpha_{i}+\beta x_{i 2}}\right)}+\frac{1 *\left(e^{\alpha_{i}+\beta x_{i 1}}\right)}{\left(1+e^{\alpha_{i}+\beta x_{i 1}}\right)\left(1+e^{\alpha_{i}+\beta x_{i 2}}\right)}} \\
\frac{e^{\alpha_{i}+\beta x_{i 2}}}{e^{\alpha_{i}+\beta x_{i 1}}+e^{\alpha_{i}+\beta x_{i 2}}}=\frac{e^{\beta x_{i 2}}}{e^{\beta x_{i 1}}+e^{\beta x_{i 2}}} .
\end{gathered}
$$

In the last step we can factor out $e^{\alpha_{1}}$ and we are left with a contribution to the likelihood function which does not include $\alpha_{1}$.

Since we have $T>2$ the problem becomes significantly more complex. Note, for example, the $P\left(\sum_{t} I_{1 t}=1\right)=$ $P(I=0) P(I=0) \ldots P P(I=1)+P(I=0) P(I=0) \ldots P(I=1) P(I=0)+\ldots$. The contribution to the likelihood of the individual who takes a credit in period $\mathrm{K}$ will be:

$$
P(\overbrace{0,0,0, \ldots, 1,0,0) / P\left(\sum I_{1 t}=1\right)}^{T}
$$

Clearly this is quite a complicated expression, although the likelihood function is still globally concave and its maximization is straightforward.

If we want to allow for $\sum_{t} I_{1 t}>1$ then we have to consider all the possible ways each of the sums could be obtained, but the fixed effect will still disappear. The number of possibilities will be 
$\left[\begin{array}{l}T \\ K\end{array}\right]$ with $K$ successes in $T$ trials, for each $k$.

Unlike a fixed effects regression model with a continuous dependent variable, we cannot "back out" estimates of the fixed effects and forecast the dependent variable. Thus we are unable to answer the question "How does increasing $x$ change the probability of making a conservation investment?". However, Chamberlain (1989) shows that

$$
\ln \left[\frac{P\left(1 \mid x=x^{\prime \prime}\right)}{P\left(0 \mid x=x^{\prime \prime}\right)}, \frac{P\left(1 \mid x=x^{\prime}\right)}{P\left(0 \mid x=x^{\prime}\right)}\right]=\beta\left(x^{\prime \prime}-x^{\prime}\right)
$$

which is of interest, and doesn't depend on $\alpha$ because the odds format makes the $\alpha^{\prime} s$ cancel. Thus we can answer the question, "By what proportion will the probability of an agent taking the action increase?".

We utilize data from tax returns for households followed over the 3 year period from 1979 through 1981. The tax data are drawn from the Ernst and Young/ University of Michigan Tax Research Database which consists of a simple random sample of returns drawn by social security Number for the tax years 1979 through 198612. The number of returns each year varies from 9235 to $46,670^{13}$. From these returns we are able to construct a three

12 We have also experimented with using the full seven year panel (1979-1985 - there is no energy investment information on the 1986 returns). The number of returns falls to roughly 6,000 which limits significantly the number of credit takers.

13 Column 5 of Table 1 provides information on the sampling frequency while column 2 shows how many returns were filed that year. 
year panel which follows 37,658 individuals. We have information on each individual's state of residence, income, number of dependents, and home mortgage and property taxes (from which we can infer home ownership status). There is also information on whether they filed an energy tax credit form, how large a credit they received and their expenditures on the conservation portion. In addition, there is detailed information on expenditures by sub-categories (e.g. storm windows, insulation). Finally, as noted above, we can compute a measure of the tax price for conservation investment using TAXSIM.

We merged tax data with data on energy prices from the Department of Energy state Energy Price and Expenditure Data System (SEPEDS). This data set has detailed price and expenditure information by state and year on the residential sector for various energy sources. In the regression results reported below, we use the price for petroleum ${ }^{14}$. We divide this price by a price index for insulation to obtain our measure of $\frac{P}{K_{1 t}}$. Note that the index varies across states but not individuals within the state. Sample statistics for the data set are provided in table 4.

Before turning to the reduced form logit results, there are several modifications of the estimating equation that we make. First we note that the theory suggests that the probability of

14 We have also experimented with using alternative price series. Results are not in any way significantly altered by which set of prices we use. 
investing depends on the price ratio net of the state tax incentive. Let $\Pi$ be the tax price of investment. For those states which offer a credit, $\Pi$ equals $1-c$, where $c$ is the state credit. For states which offer a deduction, $\Pi$ equals $1-\tau$, where $\tau$ is the individual's marginal tax rate. Then we could redefine the price as $\frac{P}{I K}$. Since the federal tax credit is in effect the entire time of our analysis, we may ignore that credit. The alternative approach and the one that we prefer is to include $\Pi$ separately in the regression. We do this to account for the possibility that the existence of the state level tax incentive itself may have some positive effect on investment. Alternatively, the incentive may not be fully understood or may require complicated record keeping. In the former case, we would expect a strong effect of $\Pi$ on the probability of investing, whereas in the latter case we'd expect a weak effect. We use the NBER TAXSIM state Tax Calculator to compute $\tau$ for individuals in states with tax deductions. 15

our model allows for differences in $\delta$ across individuals. We include two variables - heating degree days and homeownership status - to control for some of the determinants of $\delta_{1}$. Energy savings may be greater for individuals in colder states leading to a positive correlation between heating degree days and the

15 We also zero out the federal deduction for the residential energy tax credit when computing $\tau$ with TAxSIM. This ensures that there is no endogeneity between the computed tax rate and the error term in the logit regression. 
probability of investing in conservation capital.16 We include a homeownership variable since complete capitalization assures that homeowners will appropriate the entire future stream of energy savings whether they stay in the house or not. Even if capitalization is incomplete, they will receive more of the savings than renters who receive none of the savings once they move. 17 Thus we argue that homeowners should be more likely to invest than renters.

A third factor which we account for in the regression is the observation that previous studies find an inverse relationship between income and the estimated discount rate (e.g. Hausman (1979)). This could occur because of incomplete capital markets for example. We include adjusted gross income (AGI) in the regression with the expectation that it will have a positive effect on the probability of investment.

We also include a dummy variable for California in the regression. As noted above, California offers a generous credit for conservation activity ( $40 \%$ of costs net of the federal credit). This fact indicates that california residents should be less likely to claim the federal credit. In addition, we include year dummies to control for business cycle effects - important given the recessions of 1980 and 1981 .

16 Data on heading degree days by state and year are from the U.S. National Oceanic and Atmospheric Administration.

17 Moreover, if demand for rental housing is sufficiently inelastic, then renters may receive little gain while renting as the landiord may simply raise rents on the now more energy efficient rental unit. 
Finally, we exclude observations on individuals with AGI less than $\$ 10,000$ in the regressions. Many individuals in this group are not "life cycle" low income people but rather "transitory" low income due to large business 10sses. It is difficult to measure their tax price accurately; moreover, this group may be most likely to take advantage of carry forward provisions in the federal tax code which confounds our measurement of the appropriate tax price driving their investment.

our first regression result is for the pooled sample, and is reported in Table 5. The dependent variable is the dumny variable indicating the presence of a credit for conservation expenditures. We first discuss the non-price variables as their effect is relatively stable across regressions. The probability of investing goes up with income. Homeowners are more likely to take a credit as are residents of states with colder climates (more heating degree days). Each of these variables is statistically significant with p-values less than 01 . The coefficient on the dumy variable for california is consistently negative though not always statistically significant. These results are consistent with results in earlier studies (e.g. Dubin and Henson (1988) and Walsh (1989)).

Turning to the price and the tax price variables, we note that both have the wrong sign in the levels regression. One reason that the price variables may not be explaining investment very well is the presence of correlated individual effects in the 
error term. The conditional logit fixed effects regression allows us to estimate the price effects consistently in the presence of correlated fixed effects. We now turn to these estimates. The price variable continues to have the wrong sign but is now not significantly different from zero at the 5 level. However, the tax price variable now has the correct sign and is significant at the $5 \%$ level with a coefficient estimate of -2.39 . A decline in the tax price leads to an increase in the probability of investment. Below we discuss how one should interpret the economic importance of this coeficient estimate.

The last two regressions test for the robustness of the tax price coeficient estimate. We begin by dropping the year dummies to ensure that important tax price information is not being "soaked" up in the time effects. We note the statistical importance of the time dummies as well as their economic importance; business cycle effects are controlled for by these variables. There is no appreciable change in the tax price coefficient estimates and it appears that the year effects are now being captured by the price variable which now becomes highly significant ( $p$ value less than .01).

The last column tests for the possibility that the tax price effect is a spurious result. One explanation for the negative relationship between the tax price and the probability of investment is that people anticipate the beginning of a new program and delay investment until the program goes into effect. while the net change in investment would be zero with the 
implementation of a program, the estimated coefficient on the tax price variable would be negative. To test for this possibility, we constructed a dummy variable equaling one if a state had a program in effect the following year and zero otherwise. If investment shifting were occurring, we should anticipate a negative coefficient on this variable. The last regression includes this variable. The estimated coefficient on the lead tax variable is positive with a $t$ statistic about 1 indicating that tax timing is not driving our result.

How do we interpret the coefficient estimate on the tax price variable? Based on the coefficient estimate of -2.39 and a probability of investing equal to the mean of the data set (.057), a $10 \%$ point decrease in the tax price leads to a $25 \%$ increase in the probability of investing (.071). However, the point made in the simulation section still stands: Tax credits in the face of uncertain price may contribute to a large change in the log odds of the probability of investing. However this does not lead to a substantial increase in the probability itself, given the small amount of investment to begin with.

We conclude from these regression results that state tax incentives have an effect on the probability of investment which is statistically significant. However the economic importance of the programs is slight - a result consistent with the simulations based on the model of irreversible investment with price uncertainty.

Both the simulation results and the empirical estimates cast 
doubt on the effectiveness of energy tax credits in stimulating energy conservation investment in the presence of substantial energy price uncertainty. In addition, the coefficient estimates on the income and home ownership variables suggest that the benefits of the credit accrue most to higher income individuals.

\section{Conclusion}

In this paper, we've argued that residential energy conservation investment should be treated as a form of irreversible investment in the face of stochastic prices. Doing so leads to a natural explanation of the low energy conservation investment that occurred in the 1970 s and 1980 s in response to the residential energy conservation tax credit. simulation results show that price uncertainty of the magnitude observed during the $70 \mathrm{~s}$ and $80 \mathrm{~s}$ can drive conservation investment down to levels approaching zero. A tax credit of the size given by the federal residential energy tax credit will increase investment by very small amounts over a ten to twenty year horizon.

We then consider a data set on roughly 38,000 individuals followed over a three year period and find that the conservation incentive programs offered by state governments in addition to the federal program have a statistically significant effect on investment once we control for individual (fixed) effects. Based on our preferred estimate of the tax price coefficient, a 10 percentage point change in the tax price for energy investment would lead to a $24 \%$ increase in the probability of energy conservation investment. However, given the low level of 


\begin{abstract}
investment due to price uncertainty, the actual change in investment is quite low - on the order of a $1.5 \%$ increase in the probability of investment. These results suggest that a tax credit is not an effective tool for promoting conservation investment. Put differently, the expiration of Residential Energy Tax credit in 1985 had very little effect on the overall energy improvement adoption rate. If the rate of conservation investment is suboptimal from the societal perspective, then the challenge to policy makers now is to construct a more effective policy instrument to encourage conservation in the face of energy price uncertainty.
\end{abstract}




\section{Appendix}

\section{Optimal Investment When Prices}

Follow Geometric Brownian Motion

We solve the problem of choosing the optimal investment time to maximize energy savings when the price of energy and capital investment follow geometric Brownian motions. First, we note that we can apply Ito's Lemma to determine the stochastic motion of the ratio $P / K$. Letting $F(P, K)=P / K$,

$$
\begin{aligned}
& d F=F_{p} d p+F_{k} d K+ .5\left(F_{p p}(d p)^{2}+\right. \\
&\left.F_{k k}(d k)^{2}+2 F_{p k}(d P)(d K)\right)
\end{aligned}
$$

where $F_{i}$ refers to the partial derivative of $F$ with respect to $i$. substituting in the expressions for $d P$ and $d x$ (noting that $d z_{i} d z_{j}=d t$ if $i=j$ and $\rho d t$ otherwise), we obtain the result that

$$
\begin{array}{r}
d F=\left(\mu_{p}-\mu_{k}+\sigma_{k}^{2}-\rho \sigma_{p} \sigma_{k}\right)(P / K) d t+ \\
\sigma_{p}(P / K) d z_{p}-\sigma_{k}(P / K) d z_{k} .
\end{array}
$$

$F=P / K$ follows a geometric Brownian motion process with trend $(\alpha)$ equals $\left(\mu_{p}-\mu_{k}+\sigma_{k}^{2}-\rho \sigma_{p} \sigma_{k}\right)$ and variance $\left(\sigma_{0}^{2}\right)$ equal to $\left(\sigma_{P}^{2}+\sigma_{K}^{2}\right.$ $\left.-2 \rho \sigma_{\mathrm{P}} \sigma_{K}\right)$.

Once the investment is made, the value of the investment (conditional on energy price $P$ ), $V$, will equal $\delta P /\left(\gamma-\mu_{p}\right)-K$. The investment is only made if $P / K$ exceeds a trigger level $h$. At values of $P / K$ below $h^{*}$, the only value of the energy investment is in its option value, $V(P, K)$, that is

$$
V^{*}\left(P, K ; h^{*}\right)=\left\{\begin{array}{l}
V(P, K) \text { if } P / K<h^{*} \\
\frac{\delta P}{r-\mu_{p}}-K \text { if } P / K \geq h^{*}
\end{array}\right.
$$

To determine the functional form of $V$, we can construct the 
Bellman equation for the dynamic optimization problem described in equation (5). Alternatively, an arbitrage argument requires that:

$$
\gamma V d t=E(d V)
$$

Homogeneity of degree 1 in prices allows us to rewrite the value equation in terms of $P / K$ and $K$. That is

$$
V(P, K)=K V(P / K) \text {. }
$$

If we rewrite $V$ as a function of $x=P / K$, we can apply Ito's Lemma to $d V$ and obtain

$$
d v=K v^{\prime} d x+.5 K v^{\prime \prime}(d x)^{2}+v d K
$$

Substituting in (A4) above, taking expectations, dividing by dt and letting dt go to zero gives us the differential equation

$$
\left(\gamma-\mu_{k}\right) v=\alpha x v^{\prime}+.5 \sigma_{0}^{2} x^{2} v^{\prime \prime}
$$

where $\alpha$ is the drift for $d x / x$ and $\sigma_{0}^{2}$ the variance of the increment $d x / x$. We try a solution of the form $A x^{b}$ and find that a solution exists for values of b which satisfy

$$
.5 \sigma_{0}^{2} b(b-1)+\alpha b-\left(\gamma-\mu_{k}\right)=0 .
$$

Let $Q(b)=.5 \sigma_{0}^{2} b(b-1)+\alpha b-\left(\gamma-\mu_{k}\right) . Q( \pm \infty)=\infty$. Also, $Q(0)=$ $-\left(\gamma-\mu_{p}\right)$ which for historic data is likely to be negative.

Hence one root $\left(b_{1}\right)$ of the quadratic function $Q(b)$ is negative. If $Q(1)=\alpha-\left(\gamma-\mu_{p}\right)$ is also negative, the second root $\left(b_{2}\right)$ is greater ehan 1. Therefore, a general solution to the differential equation is given by

$$
v=A_{1} x^{b_{1}}+A_{2} x^{b_{2}}
$$

However, we can determine that $A_{1}$ equals zero by the following argument. Since $x$ follows a geometric Brownian motion, if it 
ever reaches zero, it will remain there indefinitely. Hence $v(0)$ must equal 0 as the option to invest is now worthless. However, since $b_{1}<0$, the first term in (Ag) will be infinite unless $A_{1}$ equals zero. Hence

$$
v=A x^{b,} \quad b>1 \text {. }
$$

We can use the smooth pasting and value matching conditions to solve for $h^{*}$. Value matching requires that the two expressions for $V$ in (A3) equate at $h^{*}$ and smooth pasting requires that they meet smoothly at $h^{*}$ (see Dixit (1991)). Incorporating these conditions yields the value of $h^{*}$ :
(A11)
$h^{*}=\frac{b}{b-1} \cdot \frac{\gamma-\mu_{p}}{\delta}$

Equivalently, it is optimal to make the investment when prices change such that

$$
\delta P \geq \frac{b}{b-1}\left(\gamma-\mu_{p}\right) K
$$

Mcdonald and Siegel (1986) show that in an investment problem of this form, it is optimal to make the investment the first time the trigger is hit. 


\section{References}

Cameron, T.A.,"A Nested Logit Model of Energy Conservation Activity By Owners of Existing single Family Dwellings," The Review of Economics and statistics, 117 (1985): 205-211.

Carlsmith, R., W. Chandler, J. McMahon and D. Santino, "Energy Efficiency: How Far Can We Go?" Oak Ridge National Laboratory, TM-11441, January 1990.

Carpenter, E.H. and Chester, S.T., "Are Federal Energy Tax Credits Effective? A Western United States Survey," The Energy Journal, 5(1984): 134-149.

Chamberlain, G. "Analysis of Covariance with Qualitative Data," Reyiew of Economic Studies 47(1980): 225-238.

Dixit, A. "Investment and Hysteresis," mimeo, Department of Economics, Princeton University, 1991.

Dubin, J.A., and Henson, S.E., "The Distributional Effects of the Federal Energy Tax Act," Resources and Energy, 10(1988): 191-212.

Griliches, z. "Hybrid Corn: An Exploration in the Economics of Technological Change," Econometrica 25(1957): 501-522.

Hausman, J. "Individual Discount Rates and the purchase and Utilization of Energy-Using Durables," Bell Journal of Economics, $10(1979): 33-54$.

Jaffee, A. and R. Stavins, "The Energy Paradox and the Diffusion of Conservation Technology," mimeo, Harvard University, December 1991.

Jovanovic, B. and s. Lach, "Entry, Exit, and Diffusion with Learning by Doing," American Economic Review, 79(1989): 690-699.

McDonald, R. and D. Siegel, "The Value of Waiting to Invest," Quarterly Journal of Economics, 101(1986): 707-727.

Peterson,H.C., "Solar Versus Conservation Tax Credits," The Enerqy Journal, pp 129-135.

Pitts,R.E. and Wittenbach,J.L., "Tax Credits as a Means of Influencing Consumer Behavior," Journal of Conșumer Research, 8(1981): 335338 .

Stoneman, P. The Economic Analysis of Technological Change, oxford University Press: Oxford, 1983 . 
Sutherland R. "Market Barriers to Energy-Efficiency Investments," The Eneray Journal, 12(1991): 15-34.

Train, K. "Discount Rates in Consumers" Energy-Related Decisions: A Review of the Literature," Energy 10(1985): 1243-53.

Walsh, M.J., "Energy Tax credits and Housing Improvement," Ph.D. Dissertation, Michigan State University, 1987.

Walsh, M.J., "Energy Tax Credits and Housing Improvement," Energy Economics, 1989, pp 275-284.

Williams, R. and M. Ross, "Drilling for Oil and Gas in our Houses," Technology Review, 1980, pp. 24-36.

U.S. Department of Energy, State Energy Price and Expenditure Report 1988, Energy Information Administration, 1988, Washington D.C.

U.S. National oceanic and Atmospheric Administration, Climatology of the United States, 1982 , U.S. Government Printing Office, washingtion D.C. 
Table 1. Fraction of Returns Taking

Residential Energy Credit

\begin{tabular}{|c|c|c|c|c|c|}
\hline \multirow{2}{*}{ Year } & \multirow[b]{2}{*}{$\begin{array}{c}\text { Number of } \\
\text { Returns } \\
(\times 1000)\end{array}$} & \multirow[b]{2}{*}{$\begin{array}{l}\text { Returns } \\
\text { w/Credit } \\
(x 1000)\end{array}$} & \multirow[b]{2}{*}{8} & \multicolumn{2}{|c|}{ Sample } \\
\hline & & & & 1 in & $q$ \\
\hline $\begin{array}{l}1978 \\
1979\end{array}$ & $\begin{array}{l}89,772 \\
92,694\end{array}$ & $\begin{array}{l}5843 \\
4775\end{array}$ & $\begin{array}{l}6.51 \\
5.15\end{array}$ & 2,053 & 5.17 \\
\hline 1980 & 93,902 & 4670 & 4.97 & 2,032 & 4.94 \\
\hline 1981 & 95,396 & 3870 & 4.06 & 2,044 & 3.90 \\
\hline 198 & 95,337 & 3136 & 3.29 & 10,323 & 3.28 \\
\hline 198 & 96,321 & NA & NA & 5,038 & 2.37 \\
\hline 1984 & 99,439 & NA & NA & 10,186 & 2.41 \\
\hline 198 & 101,660 & 2979 & 2.93 & 5,032 & 2.72 \\
\hline
\end{tabular}

Source: The first 3 columns come from Statistics of Income, various years. Column 3 shows the fraction of returns each year claiming the federal residential energy credit. The next 2 columns are computed by the authors. Column 4 shows the sampling rule for the University of Michigan/Ernst and Young Tax Panel while column 5 shows the fraction of returns each year claiming the federal residential energy credit in the panel. 
Table 2. Residential Credit Usage by Income Group

$\begin{array}{lrcr}\text { AGI } & \begin{array}{r}\text { Fraction } \\ \text { Returns }\end{array} & \begin{array}{c}\text { Fraction } \\ \text { Credit Takers }\end{array} & \begin{array}{r}\text { Fraction } \\ \text { Homeowners }\end{array} \\ 0-10 & 38.30 & 1.21 & 3.45 \\ 10-15 & 16.19 & 4.34 & 15.75 \\ 15-20 & 13.05 & 7.09 & 30.49 \\ 20-25 & 10.96 & 9.17 & 47.27 \\ 25-30 & 7.87 & 12.67 & 63.92 \\ 30-40 & 7.99 & 14.38 & 76.06 \\ 40-50 & 2.85 & 15.27 & 84.82 \\ 50-100 & 2.24 & 15.67 & 89.01 \\ 100- & 0.55 & 11.43 & 93.33\end{array}$

AGI is adjusted gross income in thousands of dollars. These statistics are computed by the authors from 38,121 returns for 1979. 
Table 3 .

Conservation Expenditures and credit by state

\begin{tabular}{|c|c|c|c|}
\hline State & Percentage & Expenditures & Credit \\
\hline $\begin{array}{l}\text { Alabama } \\
\text { Alaska }\end{array}$ & $\begin{array}{l}.060 \\
.052\end{array}$ & $\begin{array}{l}331 \\
257\end{array}$ & $\begin{array}{l}49 \\
38\end{array}$ \\
\hline Arizona & .035 & 384 & 57 \\
\hline Arkansas & .048 & 780 & 96 \\
\hline California & .021 & 762 & 101 \\
\hline Colorado & .064 & 730 & 104 \\
\hline Connecticut & .098 & 813 & 98 \\
\hline Delaware & .080 & 359 & 53 \\
\hline D.C. & .061 & 659 & 87 \\
\hline Florida & .022 & 723 & 91 \\
\hline Georgia & .039 & 428 & 58 \\
\hline Hawai & 0.0 & -- & -- \\
\hline Idaho & .052 & 266 & 40 \\
\hline Illinois & .062 & 706 & 95 \\
\hline Indiana & .048 & 641 & 91 \\
\hline Iowa & .114 & 598 & 82 \\
\hline Kansas & .055 & 449 & 58 \\
\hline Kentucky & .067 & 747 & 87 \\
\hline Louisiana & .029 & 677 & 89 \\
\hline Maine & .095 & 342 & 51 \\
\hline Maryland & .082 & 803 & 100 \\
\hline Massachusetts & .098 & 695 & 93 \\
\hline Michigan & .077 & 826 & 106 \\
\hline Minnesota & .112 & 625 & 84 \\
\hline Mississippi & .029 & 610 & 91 \\
\hline Missouri & .071 & 527 & 69 \\
\hline Montana & .098 & 587 & 88 \\
\hline Nebraska & .051 & 708 & 105 \\
\hline Nevada & .041 & 828 & 105 \\
\hline New Hampshire & .039 & 299 & 45 \\
\hline New Jersey & .086 & 695 & 94 \\
\hline New Mexico & .058 & 899 & 98 \\
\hline New York & .088 & 840 & 107 \\
\hline North Carolina & .048 & 543 & 79 \\
\hline North Dakota & .089 & 334 & 50 \\
\hline Ohio & .060 & 652 & 88 \\
\hline Oklahoma & .072 & 401 & 60 \\
\hline oregon & .063 & 878 & 127 \\
\hline Pennsylvania & .071 & 698 & 95 \\
\hline Rhode Island & .084 & 509 & 63 \\
\hline South Carolina & .043 & 570 & 82 \\
\hline South Dakota & .066 & 620 & 93 \\
\hline Tennessee & .052 & 712 & 88 \\
\hline
\end{tabular}


Table 3 - Continued

$\begin{array}{lccc}\text { State } & \text { Percentage } & \text { Expenditures } & \text { Credit } \\ & & & \\ \text { Texas } & .035 & 760 & 91 \\ \text { Utah } & .057 & 385 & 156 \\ \text { Vermont } & .049 & 1202 & 156 \\ \text { Virginia } & .060 & 606 & 85 \\ \text { Washington } & .067 & 662 & 94 \\ \text { West Virginia } & .034 & 1104 & 154 \\ \text { Wisconsin } & .093 & 453 & 62 \\ \text { Wyoming } & .046 & 586 & 88\end{array}$

This table reports the fraction of conservation credit takers and average expenditures and credit for credit takers for tax payers in the data set for 1979. Source: Authors' calculations. 
Table 4. Sumary Statistics

$\begin{array}{lcccc}\text { Variable } & \text { Mean } & \begin{array}{c}\text { Standard } \\ \text { Deviation }\end{array} & \text { Minimum } & \text { Maximum } \\ \begin{array}{l}\text { Credit Taken } \\ \text { (dummy var) }\end{array} & .057 & .233 & 0 & 1 \\ \begin{array}{l}\text { Conservation } \\ \text { Expenditures }\end{array} & 39.13 & 261.59 & 0 & 16970 \\ \begin{array}{l}\text { Credit } \\ \text { (doliars) }\end{array} & 5.04 & 28.71 & 0 & 301 \\ \begin{array}{l}\text { AGI } \\ \begin{array}{l}\text { Homeowner } \\ \text { (dumny var) }\end{array}\end{array} & 18.55 & 16.33 & -253.60 & 198.60 \\ \begin{array}{l}\text { Heating } \\ \text { Degree Days }\end{array} & .315 & .464 & 0 & 1 \\ \begin{array}{l}\text { Price } \\ \text { Tax Price }\end{array} & 7.216 & 1.410 & 4.938 & 13.498 \\ & .979 & .067 & .750 & 1.000\end{array}$

Summary statistics are for the 112,974 observations over the three year period from 1979 through 1981 . 
Table 5. Regression Results

Variable

(1)

$$
\begin{gathered}
-4.407^{\ddagger} \\
(.437)
\end{gathered}
$$

Price

Tax Price

$$
-30.718^{\ddagger}
$$$$
(7.574)
$$

$$
0.918^{\ddagger}
$$$$
\text { (.367) }
$$

Lead Tax*

AGI $(x \$ 1000)$

$$
\left(.00004^{\ddagger}\right)
$$

Homeowner

$$
\begin{aligned}
& 1.523^{\ddagger} \\
& (.035)
\end{aligned}
$$

Heating

Degree Days

$$
\begin{aligned}
& .013^{\ddagger} \\
& (.0001)
\end{aligned}
$$

California*

$$
-.463^{\ddagger}
$$$$
\text { (.110) }
$$

Year - $1979^{\circ}$

$$
.147^{\dagger}
$$$$
\text { (.061) }
$$

Year - $1980^{\circ}$

$$
\begin{gathered}
.251^{\ddagger} \\
(.035)
\end{gathered}
$$

Log-Like.

$$
\begin{gathered}
-18523.7 \\
\text { No }
\end{gathered}
$$

$$
-20.38
$$

(12.44)

$$
-2.393^{+}
$$$$
\text { (1.183) }
$$

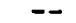

$$
.0012^{\ddagger}
$$$$
(.00025)
$$

$$
.218^{\ddagger}
$$$$
(.0052)
$$$$
-.700
$$$$
(.627)
$$$$
.196^{\dagger}
$$$$
\text { (.099) }
$$$$
.242^{\ddagger}
$$$$
(.043)
$$$$
(.00025)
$$

$$
-2.102
$$$$
\text { (1.180) }
$$$$
-30.35^{\ddagger}
$$

$-22.46$ $(12.63)$

$-2.577^{\dagger}$

(1.197)

.101 (.096)

$.0012 \ddagger$

$(.00025)$

$$
\begin{array}{r}
.944^{\ddagger} \\
(.089)
\end{array}
$$

$$
.0012^{\ddagger}
$$

Fixed Effects

$-4451.0$

Yes
.9127

(.088)

$.942^{\ddagger}$

(.089)

$.021^{\ddagger}$

$(.005)$

$(.050)$

$-.723$

$-.399$

(.627)

(.618)

.181

(101)

$.238^{\ddagger}$

$-4467.1$

$-4450.4$

Yes

Yes

Fixed Ef fects

+ - significant at the 58 level

* - significant at the 1 level

Regression results are for individuals in the 50 states plus the District of Columbia followed over the three year period from 1979 through 1981. Standard errors are reported in parentheses. An asterisk on a variable indicates a dummy variable. 

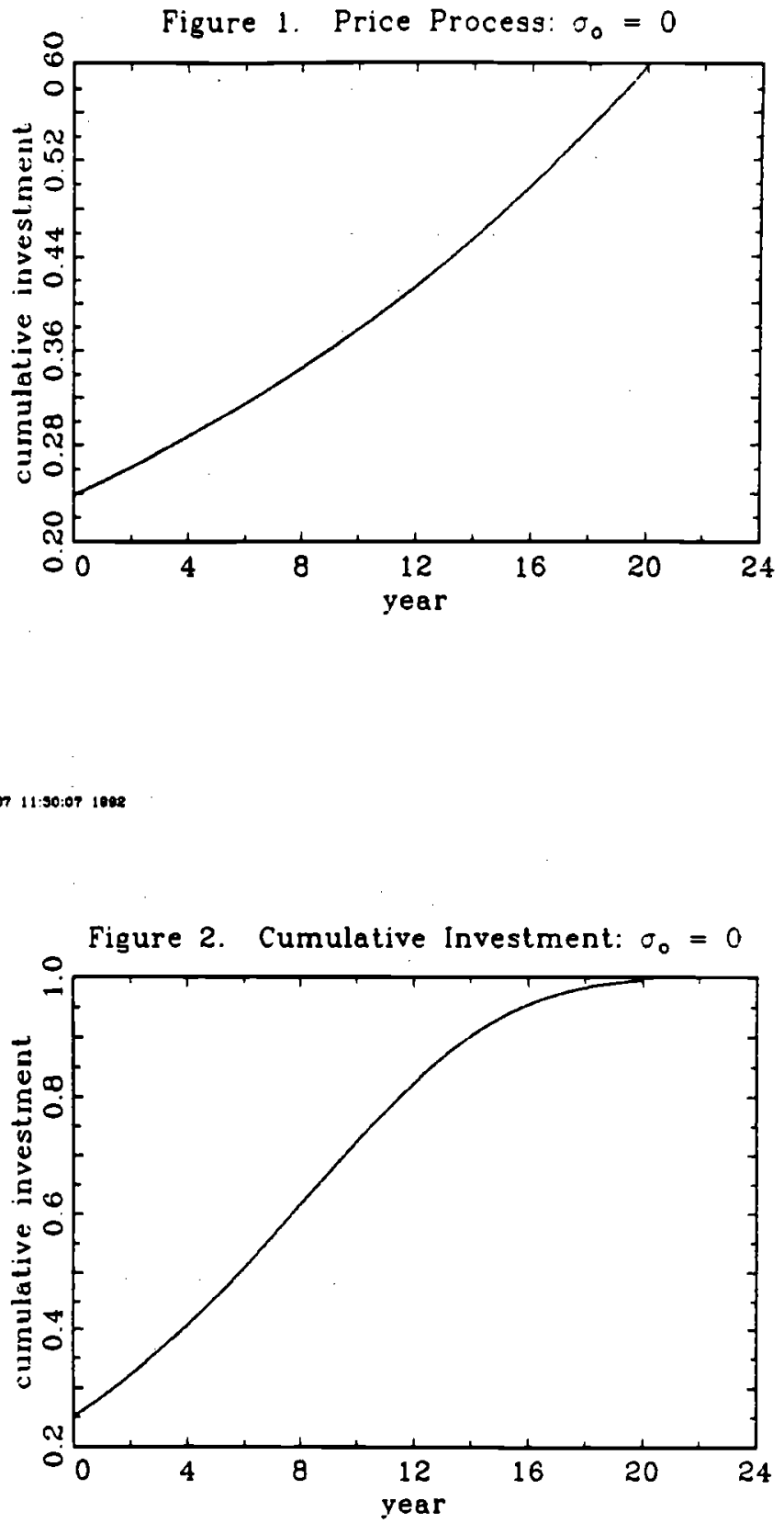
Figure 3. Price Process: $\sigma_{0}=0.093$

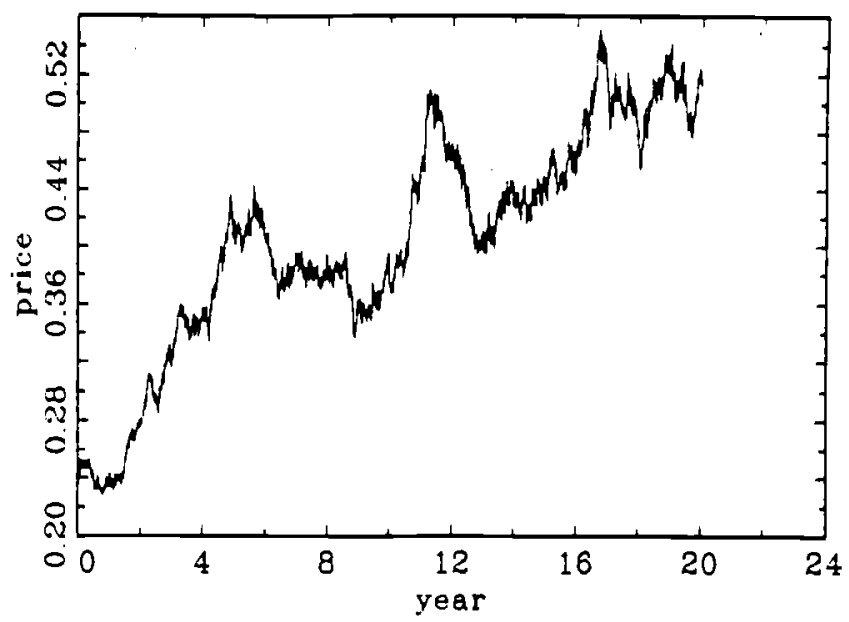

Figure 4. Cumulative Investment: $\sigma_{0}=0.093$

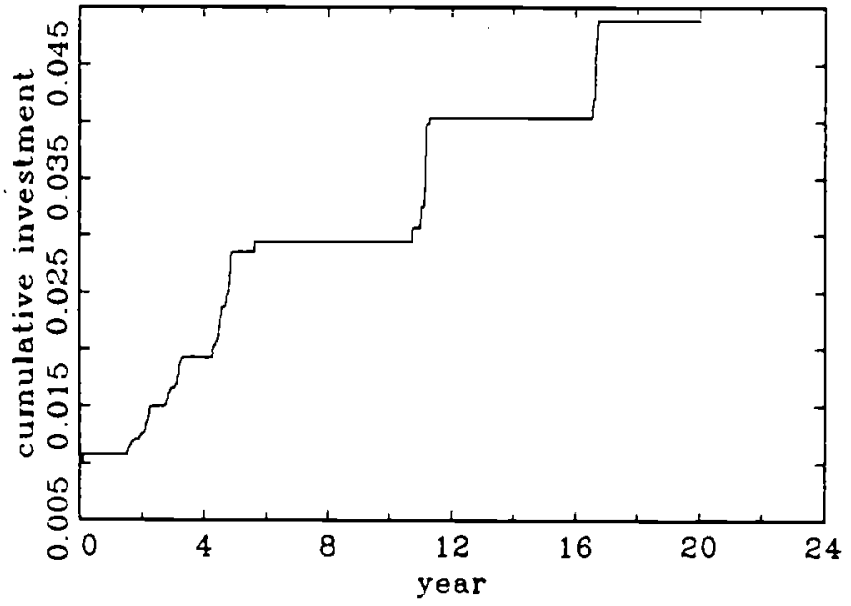


Figure 5. Cumlative Irvestment: $\sigma_{0}=0.093$ 500 Replications

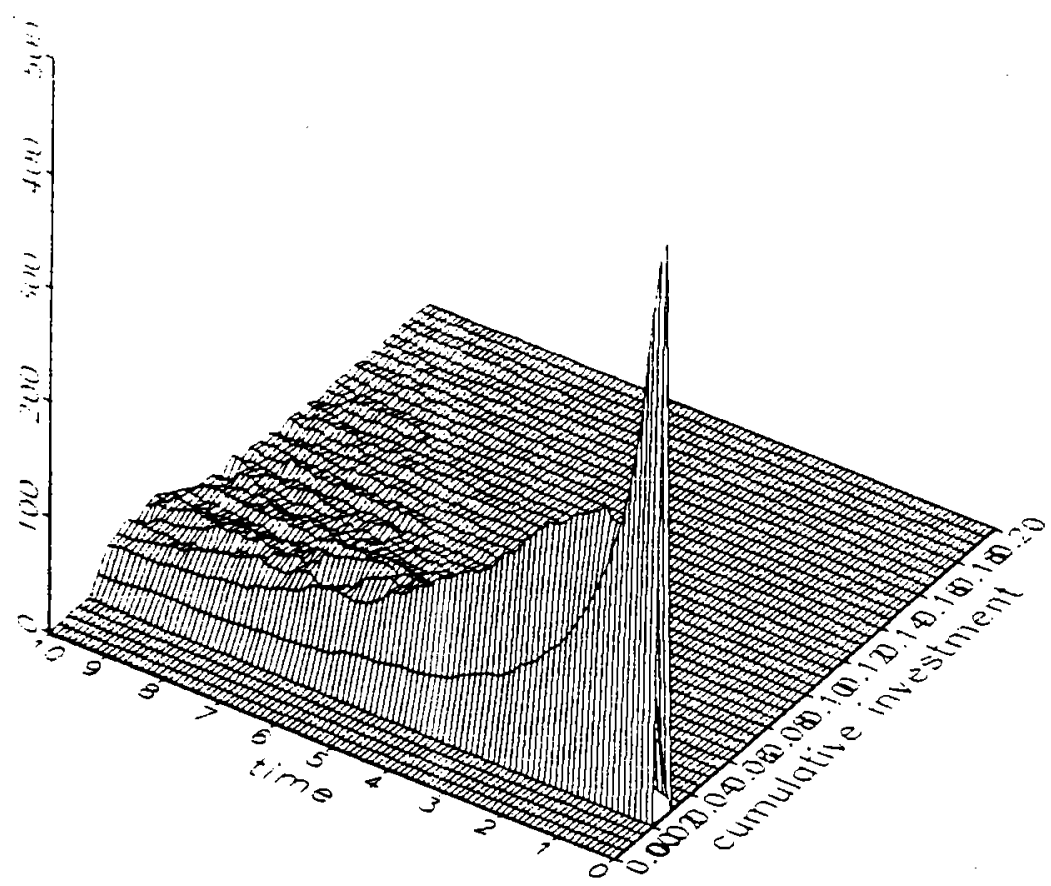



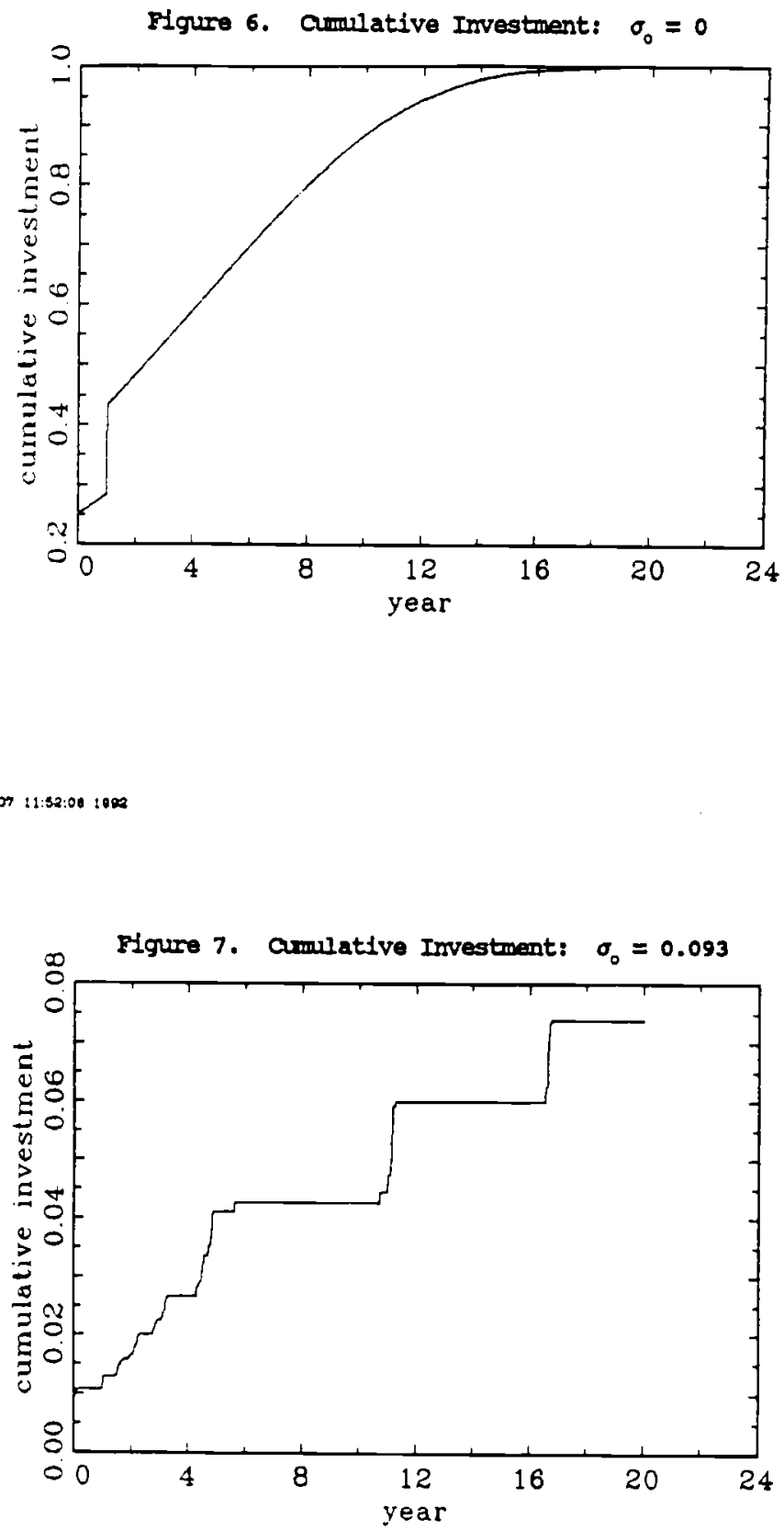